\title{
Que la pandemia no nos robe la humanidad. Paraguayos y paraguayas residentes en el extranjero y su derecho a regresar a su país
}

\section{May the pandemic not rob us of humanity. Paraguayans living abroad and their right to return to their country}

\author{
Patricia Cristaldo $^{a}$, Rosa Ruffinelli ${ }^{a}$, Belinda García ${ }^{a}$, Alvaro Lo Bianco ${ }^{b}$
}

\begin{abstract}
Resumen
En este artículo académico, se presenta la situación de los paraguayos residentes en el exterior y la violencia estructural ejercida por el Estado hacia los compatriotas, que al igual que todos los ciudadanos, han sido gravemente afectados por la pandemia y en especial este grupo en particular, que se encuentran lejos de sus familias, de sus raíces, del lugar donde en medio de la adversidad, sienten que deben volver. Se realizó un relevamiento bibliográfico sobre la legislación vigente a nivel nacional e internacional que garantizan los derechos de todos ciudadano paraguayo aun si se encontrara residiendo en el extranjero, describiremos las medidas sanitarias tomadas por el gobierno para mitigar el avance de la pandemia en nuestro país y el impacto de las mismas en la vida de los connacionales residentes en el extranjero, las restricciones impuestas y la legalidad de las mismas, principalmente ante las innumerables denuncias de uso indebido de las fuerza por parte de policías y militares hacia la población en general y la respuesta brindadas por el Estado Paraguayo a los conciudadanos migrantes, principalmente en cuanto a albergues y hoteles albergues.
\end{abstract}

Palabras clave: derechos humanos, connacionales, violencia estructural, pandemia, migrantes.

\begin{abstract}
This academic article presents the situation of Paraguayans living abroad and the structural violence exercised by the State towards compatriots, who, like all citizens, have been seriously affected by the pandemic and especially this particular group, who are far from their families, from their roots, from the place where in the midst of adversity, they feel they must return. A bibliographic survey was carried out on the legislation in force at the national and international level that guarantee the rights of all Paraguayan citizens even if they were residing abroad, we will describe the health measures taken
\end{abstract}

a Universidad Nacional de Asunción, Facultad de Ciencias Sociales, Paraguay.

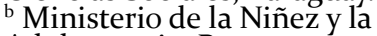
Adolescencia, Paraguay.

Correspondencia a: cristaldopatricia@gmail.com

Recibido:

27 de agosto de 2020 Aceptado:

22 de octubre de 2020

(c) (1)

Artículo publicado en acceso abierto bajo la Licencia Creative Commons.

Cita:

Cristaldo, P., Ruffinelli, R., García, B., \& Lo Bianco, A. (2020). Que la pandemia no nos robe la humanidad. Paraguayos y paraguayas residentes en el extranjero y su derecho a regresar a su país. Kera Yvoty: reflexiones sobre la cuestion social, 5 , 71-84. 
Cristando, P., Ruffinelli, R., García, B., \& Lo Bianco, A. Que la pandemia no nos robe la humanidad.

Paraguayos y paraguayas residentes en el extranjero y su derecho a regresar a su país.

by the government to mitigate the advance of the pandemic in our country and their impact on the lives of nationals residing abroad, the restrictions imposed and their legality, mainly in light of the countless complaints of improper use of force by the police and military against the general population and the response provided by the Paraguayan State to fellow migrants, mainly in terms of hostels and hotels.

Keywords: human rights, nationals, structural violence, pandemic, migrants.

\section{Introducción}

El problema de la migración de paraguayos al exterior, no es una realidad nueva, sino recurrente en nuestra historia, principalmente por dos motivos, el exilio por razones políticas y el económico.

Eligio Ayala en su libro Migraciones describe como la migración de paraguayos al exterior fue dándose paulatinamente pos guerra de la triple alianza, motivada por sobre todo por la inestabilidad política y económica del Paraguay de inicios del siglo XX (Ayala, 2006).

La revolución en bicicleta (Mempo Giardini, 2019) sostiene que el inicio de la diáspora de migrantes paraguayos se remonta a finales de 1940, luego de culminar la guerra civil del 47 , este fue esencialmente por motivos políticos.

La segunda oleada migrante se da bajo la larga tiranía de Alfredo Stroessner, como se describe en el informe de la Comisión de Verdad y Justicia (2006), miles de paraguayos sufrieron el exilio político y también económico.

Una tercera oleada migratoria se dio en la década de los 9o, luego del vaciamiento del estado por una cúpula colorada, (Méndez , 2008). También se registró un importante número de migrantes a España, a inicios del siglo XXI, en gran medida debido a la crisis de finales de los 90 e inicio del siglo en Argentina (Benítez Cabral, 2020).

Es sabido el efecto que produce el desarraigo y las dificultades que conlleva el estar lejos de la patria, de la familia, de la casa, etc. El termino desarraigo es sinónimo del proceso de extracción de la raíz de una planta, comparando la perdida de raíz de esta, con alguien que tuvo que alejarse de su tierra por diversos motivos (Bourdieu, 2017).

El punto en común en todos los casos, es que no se registran datos de que las familias que migraron hayan vuelto cuando las cosas mejoraron en el país, Por ende, vemos familias enteras paraguayas y sus descendientes, asentarse en la Argentina y en España principalmente.

En los momentos de crisis, cuando la vida está en riesgo, es cuando nace el sentimiento del Hechagau (añoranza) y el retorno a tu país se vuelve una alternativa hasta de vida. En tanto América Latina se convirtió en las últimas semanas en el epicentro de la pandemia de coronavirus a nivel mundial -entre los 15 países del mundo con mayor número de casos confirmados hay cuatro latinoamericanos: Brasil, Perú, Chile y México, de acuerdo con cifras de la Universidad John Hopkins de EE.UU.-, Paraguay vuelve a la normalidad después de tres meses de confinamiento (Attanasio, 2020).

En tanto compatriotas en el extranjero piden a la ciudadanía paraguaya consciencia y respetar las medidas sanitarias, como única alternativa contra el virus. Todos coincidieron en que si bien es bastante alentador que el Gobierno Nacional haya tomado medidas de forma temprana para evitar la propagación del Covid-19, es sumamente importante que la ciudadanía tome consciencia de la gravedad de la enfermedad y respete las normas sanitarias (TRECE, 2020), Manifiestan que lo principal es respetar el aislamiento, para reducir al mínimo la capacidad de contagio 
del virus. Osmar Suarez, residente en Italia, indicó que, si en Paraguay no se respetan las medidas de seguridad, se sufrirán graves consecuencias. "Tengo miedo porque en Paraguay tenemos menos recursos" (TRECE, 2020).

\section{Situación de connacionales residentes en el exterior, durante la pandemia}

Tras el inicio de la pandemia varios países tomaron la decisión de declarar cuarentena y obligar a su población a aislarse en sus casas, como medida para luchar contra la propagación del virus entre sus habitantes. Miles de paraguayos residentes en el exterior, no están exentos de esta situación y comparten vía redes sociales su forma de vivir la cuarentena, lo que en muchos casos genero pérdidas económicas, falta de ingreso y también no poder acceder a programas sociales en los territorios en donde se encontraban debido a la informalidad del trabajo, o la pérdida del ingreso.

Según informe de cancillería 9025 conciudadanos regresaron a nuestro país hasta el mes de julio, y entre las principales causas de dicha decisión es que han perdido sus empleos y por ende se han quedado sin recursos económicos para seguir subsistiendo, entre tanto existe un grupo que ha viajado a países vecinos para realizar tratamientos médicos, no pudiendo retornar debido a la declaración de pandemia. (ABC, Color, 2020a)

Otro informe de cancillería reveló que veinticinco mil conciudadanos desean regresar a nuestro país y entre las principales causas de dicha decisión es que han perdido sus empleos y por ende se han quedado sin recursos económicos para seguir subsistiendo, otro de los factores predominantes del motivo de retorno de los compatriotas es pánico en torno a la pandemia y la angustia de encontrarse lejos de sus familiares (ABC, Color, 202ob).

Cabe resaltar que América es el continente más desigual del planeta que se caracteriza por profundas brechas sociales de pobreza y desigualdad, con índices de inseguridad y violencia principalmente por razones de género, raza o etnia, sin precedentes en los últimos años, hechos que suponen un mayor reto para los estados para hacer frente a la pandemia. Muchos de los factores mencionados más arriba han obligado a miles de ciudadanos a migrar a otros países en busca de mejores condiciones de vida.

Los decretos que entran en vigencia desde el inicio de la pandemia y que afectan a los ciudadanos residentes en el extranjero son los siguientes;

-Decretos del Poder Ejecutivo $\mathrm{N}^{\circ}$ 3458 de 16 de marzo de 2020.

-Decretos del Poder Ejecutivo $\mathrm{N}^{\circ}$ 3465 de 17 de marzo de 2020 ,

-Decretos del Poder Ejecutivo $\mathrm{N}^{\circ}$ 3526 de 9 de abril de 2020, todos ellos relacionados a la Ley $\mathrm{N}^{\circ} 836 / 1980$ Código Sanitario, en particular en sus Arts. 13, 25-29, 31-33 y 38 y la Resoluciones SG $\mathrm{N}^{\circ}$ $173 / 2020$ y N $N^{\circ} 228 / 2020$ del MSPyBS.

Desde el ingreso de la pandemia en nuestro País, el poder ejecutivo ha tomado una serie de medidas sanitarias, tendientes a enlentecer el contagio, ganar tiempo para preparar el sistema de salud con equipamiento, insumos y personal de salud capacitado para atender a los infectados, (muchas son las críticas de todos los sectores sobre este aspecto ya que a pesar de contar con el dinero y el tiempo necesario, el Ministerio de Salud no ha podido preparar al sistema de salud, por lo numerosos hechos de corrupción entorno a las compras de insumos, medicamentos, etc.). Para ello el presidente de la república ha emitido Decretos cuyas prohibiciones afectan seriamente la plena vigencia de los derechos humanos y la pérdida de libertades como ciudadanos y ciudadanas. Estos decretos han afectado igualmente a los conciudadanos residentes en el exterior del País que por las medidas sanitarias resueltas en los países donde se encuentran residiendo no han podido retornar a nuestro país o han quedado varados en las 
Cristando, P., Ruffinelli, R., García, B., \& Lo Bianco, A. Que la pandemia no nos robe la humanidad.

Paraguayos y paraguayas residentes en el extranjero y su derecho a regresar a su país.

fronteras, en espera de una respuesta del Estado Paraguayo.

El presidente de la república ha asignado a las Fuerzas Armadas y a la Policía Nacional para garantizar el estricto cumplimiento de las medidas sanitarias quienes a su vez ha realizado un sinfín de detenciones ilegales, hechos de tortura, tratos crueles, inhumanos y degradantes contra la población paraguaya. Situación que han agudizado la pérdida de libertades fundamentales y han puesto en serio riesgo el estado de derecho.

El gobierno impone el aislamiento social como medio de prevención para evitar la propagación del virus, tal aislamiento trae consecuencias serias sobre la salud mental de las personas ya que el encierro obligatorio se dio en forma abrupta y sin contar con un equipo especializado de contención.

\section{Derechos vulnerados por el estado paraguayo, durante la pandemia}

La Constitución Nacional, Art. 5 expresa: Nadie será sometido a torturas ni a penas o tratos crueles, inhumanos o degradantes. El genocidio y la tortura, así como la desaparición forzosa de personas, el secuestro y el homicidio por razones políticas son imprescriptibles, así como establece como los Art. 9, 11,12, 19 y 21.

Art. 32: Las personas tienen derecho a reunirse y a manifestarse pacíficamente, sin armas y con fines lícitos, sin necesidad de permiso, así como el derecho a no ser obligadas a participar de tales actos.

Art. 41: Todo paraguayo tienen derecho a residir en su Patria. Los habitantes pueden transitar libremente por el territorio nacional, cambiar de domicilio o de residencia, ausentarse de la República o volver a ella.

Art. 68: El Estado protegerá y promoverá la salud como derecho fundamental de la persona y en interés de la comunidad. Nadie será privado de asistencia pública para prevenir o tratar enfermedades, pestes o plagas, y de socorro en los casos de catástrofes y de accidentes.

Convención contra la Tortura y Otros Tratos o Penas Crueles, Inhumanos o Degradantes de la ONU, Ley $\mathrm{N}^{\circ}$ 69/90, Art 5: Nadie será sujeto a tortura o a cualquier otro tratamiento degradante, inhumano o castigo.

Resolución 01/2020 Pandemia y Derechos Humanos en las Américas (Adoptada por la CIDH el 10 de abril de 2020), que establece estándares de derechos humanos.

\section{Restricciones y legalidad de las mismas}

En nuestro país las medidas sanitarias han puesto en serio riesgo la democracia y el estado de derecho, condiciones necesarias para la vigencia plena de los derechos humanos, muestra de ellos, son las condiciones crueles, inhumanas y degradantes que viven nuestros compatriotas residentes en el extranjero, en su intento desesperado por volver a su patria.

Mucho se ha debatido sobre la legalidad de las restricciones impuestas por los gobiernos, más allá de los fines para los que fueron impuestas estas restricciones ya que claramente viola derechos constitucionales y en particular si nos referimos a los compatriotas residentes en el extranjero, cuyas vidas han sido puestas en serio peligro al no tener respuestas efectivas por parte del Estado paraguayo. Ante la larga espera de los compatriotas en las fronteras del Brasil, encontrándose hacinados y a la intemperie sin acceso a establecimientos sanitarios, aseo y alimentación digna, sobre el puente de la amistad los expuso a un contagio masivo y cuando lograron ingresar al país en su mayoría ya se encontraban contagiados. La misma suerte han sufrido los demás compatriotas en otras ciudades fronterizas.

Según la resolución $\mathrm{N}^{\circ}$ 01/2020 $\mathrm{CIDH}$ "En cuanto a las medidas de contención con el fin de enfrentary prevenir los efectos de la 
pandemia, la CIDH ha observado que se han suspendido y restringido algunos derechos, y en otros casos se han declarado "estados de emergencia”, "estados de excepción", "estados de catástrofe por calamidad pública", o "emergencia sanitaria", a través de decretos presidenciales y normativa de diversa naturaleza jurídica con el fin de proteger la salud pública y evitar el incremento de contagios. Asimismo, se han establecido medidas de distinta naturaleza que restringen los derechos de la libertad de expresión, el derecho de acceso a la información pública, la libertad personal, la inviolabilidad del domicilio, el derecho a la propiedad privada; y se ha recurrido al uso de tecnología de vigilancia para rastrear la propagación del coronavirus, y al almacenamiento de datos de forma masiva" (CIDH, 2020).

La CIDH en su resolución $\mathrm{N}^{\circ}$ 01/2020 menciona taxativamente "La Comisión Interamericana de Derechos Humanos (CIDH), con el apoyo de sus Relatorías Especiales sobre los Derechos Económicos, Sociales, Culturales y Ambientales y sobre Libertad de Expresión, en ejercicio de su mandato, adopta la presente resolución con estándares y recomendaciones bajo la convicción de que las medidas adoptadas por los Estados en la atención y contención de la pandemia deben tener como centro el pleno respeto de los derechos humanos".

Igualmente, la CIDH, en relación a las personas migrantes ha resuelto recomendar a los estados parte los siguientes puntos;

58. Evitar el empleo de estrategias de detención migratoria y otras medidas que aumenten los riesgos de contaminación y propagación de la enfermedad generada por el COVID-19 y la vulnerabilidad de las personas en situación de movilidad humana como deportaciones o expulsiones colectivas, o cualquier forma de devolución que sea ejecutada sin la debida coordinación y verificación de las condiciones sanitarias correspondientes, garantizando las condiciones para que estas personas y sus familias puedan salvaguardar su derecho a la salud sin ninguna discriminación. En este sentido, se deben implementar rápidamente mecanismos para proporcionar la liberación de las personas que actualmente se encuentran en centros de detención. (CIDH 2020, p. 18)

59. Abstenerse de implementar medidas que puedan obstaculizar, intimidar y desestimular el acceso de las personas en situación de movilidad humana a los programas, servicios y políticas de respuesta y atención ante la pandemia del COVID-19, tales como acciones de control migratorio o represión en las cercanías de hospitales o albergues, así como el intercambio de información de servicios médico hospitalarios con autoridades migratorias con carácter represivo. (CIDH 2020, p. 18)

6o. Garantizar el derecho de regreso y la migración de retorno a los Estados y territorios de origen o nacionalidad, a través de acciones de cooperación, intercambio de información y 19 apoyo logístico entre los Estados correspondientes, con atención a los protocolos sanitarios requeridos $y$ considerando de manera particular el derecho de las personas apátridas de retornar a los países de residencia habitual, y garantizando el principio de respeto a la unidad familiar. (CIDH 2020, p. 19)

61. Implementar medidas para prevenir y combatir la xenofobia y la estigmatización de las personas en situación de movilidad humana en el marco de la pandemia, impulsando acciones de sensibilización a través de campañas y otros instrumentos de comunicación y elaborando protocolos y procedimientos específicos de protección $y$ atención dirigidos a niñas, niños y adolescentes migrantes y refugiados, en especial, proveyendo los 
Cristando, P., Ruffinelli, R., García, B., \& Lo Bianco, A. Que la pandemia no nos robe la humanidad. Paraguayos y paraguayas residentes en el extranjero y su derecho a regresar a su país.

mecanismos específicos de asistencia a aquellas personas que se encuentran separadas o sin compañía. 62. Incluir expresamente las poblaciones en situación de movilidad humana en las políticas y acciones de recuperación económica que se hagan necesarias en todos los momentos de la crisis generada por la pandemia. (CIDH 2020, p. 19)

\section{Respuestas del Estado paraguayo}

La respuesta del Estado Paraguayo ante la pandemia SARS-CoV-2 para connacionales residentes en el exterior se torna diversa y en aumento según necesidades que surgen en la misma medida que se desarrolla la pandemia, hablando de efectividad y eficiencia sin contar con mediciones o resultados cuantitativos $\mathrm{y}$ cualitativos.

En marzo aparece en el país el primer caso de COVID-19, el Estado emite la Ley $\mathrm{N}^{\circ}$ $6524 / 2020$, declara estado de emergencia en todo el territorio de la República del Paraguay ante la pandemia declarada por la organización mundial de la salud a causa del COVID-19 o coronavirus y se establecen medidas administrativas, fiscales $y$ financieras. En la referida ley se afectan a instituciones públicas relacionadas a la cartera ejecutiva, entre estas no se encuentra el Ministerio de Relaciones exteriores pero en el art. 3 de la misma ley dispone que el Poder Ejecutivo podrá determinar otras instituciones afectadas en el marco de lo dispuesto en el Artículo $2^{\circ}$ de la presente ley.

La Dirección General de Migraciones del Ministerio del Interior (DGM, 2020) emitía un comunicado respecto al cierre total de fronteras y que solo se encontraba permitido el de ingreso de cargas $y$ mercancías, para el abastecimiento de la población, además que estaría permitido el egreso del país de los extranjeros que así lo deseen, aunque los mismos ya no podrán volver a ingresar mientras dure la medida.

El Decreto $\mathrm{N}^{\circ} 3465 / 2020$, ampliaba el Art. 3 del Decreto $\mathrm{N}^{\circ} 3458$ del 16 de marzo de
2020, Por el cual se dispone el cierre parcial y temporal de puestos De control migratorio en frontera, como medida ante el riesgo de Expansión del coronavirus (COVID-19) dando expresamente a la Dirección General de Migraciones, la potestad del ingreso al país a miembros de Misiones Diplomáticas y Organismos Internacionales con ingresos autorizados, nacionales y extranjeros residentes en el Paraguay, y restringirá el egreso de los mismos fuera del territorio nacional.

El Jefe de Estado ha encomendado a la Cancillería Nacional articular con las Embajadas y Consulados en el exterior los mecanismos pertinentes para brindar la asistencia necesaria a los compatriotas en dicha situación durante el periodo de restricción de su ingreso al país y coordinar su retorno a partir de la fecha de culminación de esta restricción, adoptada bajo el amparo de la Constitución Nacional, Artículo $4^{\circ}$ Del Derecho a la Vida. (DGM, 2020)

Las dos instituciones encargadas en la atención específica a los connacionales a nivel ministerial son porun ladoel Ministerio del interior en su Dirección General de Migraciones DGM y el Ministerio de Relaciones exteriores MRE en general, pero Dirección de Atención a las Comunidades Paraguayas en el Exterior es quien maneja la atención general a los connacionales, el formulario de Solicitud de Asistencia está gestionada por la dirección (MRE, 2020) allí se realiza la carga de datos respecto a información personal, antecedentes del viaje y detalles de la solicitud como también la Secretaría de Desarrollo para Repatriados y Refugiados Connacionales (SEDERREC).

Más adelante otras instituciones y organismos del Estado hacen parte de la atención a los connacionales que lograron retornar como lo son la Secretaria de Emergencia Nacional (SEN), las Fuerzas Armadas de la nación (FF.AA) y el Consejo de Defensa Nacional (CODENA), además de las ya mencionadas. 
La respuesta debió ser urgente ya que la pandemia se expandió por América Latina en los meses de marzo y abril, ya atravesando unos meses a Europa como en Asia.

Se tomaron acciones como vuelos humanitarios, y el establecimiento de albergues en sus modalidades públicos y o privados denominados Hoteles Albergues. El establecimiento de estos albergues se consideró como fundamental como contención ante una propagación masiva del total país ante una posible circulación comunitaria del virus, y además este tipo de aislamiento permitió identificar casos asintomáticos (IPA, 2020).

En estos alberges connacionales retornados deberían cumplir los días obligatorios de cuarentena además de realizarse la prueba de COVID-19, se instauró dos tipos de población en interno, se asumía que los que no presentaban síntomas eran casos negativos, quienes contaron con controles sanitarios menores, y el otro grupo poblacional que corresponde a quienes dieron positivo a la prueba y que requieren un nivel mayor de aislamiento. (IPA, 2020)

El Consulado General de la República del Paraguay en Buenos Aires, República Argentina, en su comunicado $\mathrm{N}^{\circ} 2 \mathrm{O}$ mencionaba que se estaba trabajando en un retorno planificado de paraguayos VARADOS (no residentes) en el exterior y que se daba prioridad a menores de edad que siguen tratamiento médico, adultos mayores, personas con enfermedades graves y personas con discapacidad y que estos eran lineamientos del CODENA. (MRE, 2020) y que el consulado de origen de los connacionales es quien proveerá de los datos para analizar caso por caso (eldiario, 2020)

Resulta sumamente dificultoso dar respuesta material y concreta a todas y cada una de las solicitudes, pues, además de los criterios ya citados, deben ser respetadas las normativas y restricciones de emergencia establecidas en la República
Argentina con relación a la circulación de personas, como también, aguardar la autorización del CODENA para la apertura y disposición de locales adecuados para realizar la cuarentena obligatoria de 14 días al ingresar a territorio nacional. (MRE, 2020)

\section{Los albergues Made in Paraguay}

Cuando se anunció el cierre de las fronteras en marzo de 2020 , se generó un nuevo escenario, sin embargo, la respuesta del estado, no fue diferente a la que venía siendo, marcada por la improvisación y el desamparo, hacia los connacionales que más allá de los motivos que los llevó a migrar a tierras extranjeras, durante la pandemia COVID-19 deseaban retornar a nuestro país.

Con el transcurso de los meses se fueron organizando los viajes humanitarios y los alojamientos en albergues y hoteles. Estos últimos con un fuerte componente de clase, los albergues para los pobres y los hoteles para los adinerados.

Las condiciones en los albergues no siempre fueron las mejores, ni siquiera por la calidad edilicia de los mismos y las comodidades. La vulneración de derechos en los mismos, está relacionada al poco respeto a la privacidad, la no diferenciación correcta de los espacios, el custodio amenazante de los militares en muchos casos, la poca socialización de información por parte del Ministerio de Salud, entre otras cosas.

No fue fácil la travesía por la que pasaron los connacionales, ni al momento de irse y mucho menos al momento en que desearon regresar.

Los Primeros albergues fueron establecidos en Alto Paraná considerado departamento crítico, por la cercanía con el Brasil, se establecían albergues sanitarios en Hernandarias, todos relacionados con predios de la iglesia católica (La Nación, 202ob) mientras que en el Departamento Central se estableció en la Academia Militar en la ciudad de Capiatá (IP, 2020). Allí se 
Cristando, P., Ruffinelli, R., García, B., \& Lo Bianco, A. Que la pandemia no nos robe la humanidad.

Paraguayos y paraguayas residentes en el extranjero y su derecho a regresar a su país.

ubicó al primer grupo de 72 connacionales retornados y se habían registrado un total de 522 personas, 61 eran menores de edad (IP, 2020).

De acuerdo a publicaciones en abril había un aproximado 1.600 connacionales varados en el exterior y que la dirección General de Asuntos consulares y la Dirección de Atención a Comunidades Paraguayas en el Exterior registran "situaciones especiales" que se establecían como perdidas de vuelos, cancelación de contratos laborales o vulnerabilidad (Abc Color, 2020c).

Ya en abril se registraban 6o situaciones de perdida de trabajo, además de otras 48 solicitudes de estudiantes de la Universidad Federal de la Integración Latinoamericana; como así también de jugadores de futbol profesional partes de la APF, ingresaban a la lista de desempleados a nivel mundial y esperaban retornar al país (Última Hora, 2020) lo que dejaba un panorama general de la diversidad de connacionales solicitando asistencia del Estado.

Además, se recibieron solicitudes globalmente, de América Latina, Brasil, Argentina, Chile, Bolivia, de Centro América, Panamá, Guatemala, Guyana Francesa, en Europa principalmente de España, en Madrid, Málaga y Barcelona donde los vuelos para el mes siguiente se cotizaban en el aproximado de $€$. 650 por persona que debían adquirirse a través de agencias de viajes pese a que se comunicaba como una gestión de la embajada del Paraguay en España (IP, 2020a).

También llegaron solicitudes desde Francia, Inglaterra, Suecia, Noruega, Escocia, también el continente asiático en los países de Egipto, Japón, Corea, Líbano, Filipinas. También se registraron peticiones de Indonesia, Nueva Zelanda (Abc Color, 2020c).

Desde el 30 de abril se establecieron los tests obligatorios en albergues en las primeras 48 horas de su ingreso, para descartar casos asintomáticos (IP, 2020b).

Estas “circunstancias extraordinarias” obligaban al estado a limitar las plazas en los albergue, y que había una prioridad para la entrada de niños y mujeres mientras se analizan las circunstancias del resto de ciudadanos sobre todo en Ciudad del Este donde había una media de 200 paraguayos en espera de cruce del Puente de la Amistad para el retorno pero que también habían "casos complicados" refiriendose a connacionales con antecedentes o fueron expulsados de Brasil pordelitos relacionados con el contrabando. Federico González del Ministerio de Relaciones Exteriores mencionaba que "muchos de los que entren no irán a albergues sino a centros de reclusión" (EFE, 2020) desconociendo así la emergencia penitenciaria que se desarrolla en simultaneo como otra pandemia en el país.

Además se dio el cierre del albergue transitorio en zona primaria del Puente de la Amistad, porque se consideraba que no existían condiciones para continuar con el ingreso de connacionales de forma ordenada y planificada (IP, 2020c) pese a que un $85 \%$ del total del ingreso en el mes de abril, se dio desde el Brasil por el puente de la Amistad, pero llegaron desde Argentina, y Bolivia (IP, 2020d).

Un dato no menor es que en el mes de mayo se dieron a conocer más albergues públicos instalados en la División de Tratamiento y Rehabilitación de Adicciones (DITRES) de la SENAD, predios de la Armada paraguaya, el Hogar Carlota Parmerola, los connacionales retornaban a sus hogares luego del cumplimiento del aislamiento obligatorio (HOY, 2020a). Las modalidades de los testeos realizados a nivel país, se mantienen con reportes de 154 casos positivos, los internados con problemas respiratorios y los connacionales retornados del exterior.

En el mismo mes se registran la llegada de connacionales de Argentina, Uruguay, Chile como repatriados desde Estados Unidos con un costo aproximado de $\$ 800$ por persona que también debía ser costado por las personas interesadas como así también la reserva del hotel, 
considerado requisito ineludible y debían presentarse a Dirección de Atención de Comunidades Paraguayas en el Extranjero del Ministerio de Relaciones Exteriores, con copia al Consulado paraguayo de su circunscripción, indicando como tema "Vuelo Especial a Paraguay" en este caso la Sección Consular de la Embajada en Washington DC, Consulado General en Los Ángeles, Consulado General en Nueva York, y el Consulado General en Miami (IP, 2020e).

El Centro de Coordinación Interinstitucional (CCI) en conferencia de prensa daba a conocer que habían ingresado 3.821 connacionales hasta el 23 de mayo y que 1.776 ciudadanos paraguayos se encontraban en los centros de albergues y de los cuales 200 personas se encuentran en los 16 hoteles albergues y que se esperaba ya iniciar el retorno de connacionales de Europa (La Nación, 2020a), Sin embargo el 5 mayo se registra la comunicación del MRE con 1.936 connacionales retornados cumpliendo la cuarentena, mientras se registraba un total de 2.810 ingresos al país desde el cierre de fronteras (IP, 2020e).

Los connacionales varados en Argentina eran 630 solicitudes de repatriación, y en que aproximado unas 300 a 350 personas del grupo quedaron desempleadas y estaban viviendo hace tiempo en el vecino país, y que las demás correspondían a la migración para realizarse tratamientos de salud y que el consulado había recibido \$5.00o desde el MRE para asistir a unas 20.000 familias en estado de vulnerabilidad pero que estos fondos ya habían sido ejecutados (HOY, 202ob) según la cónsul paraguaya en Buenos Aires.

En simultaneo la colectividad paraguaya en el mencionado país exigían al estado atención urgente, Migrar es un derecho regresar también (ABC, 2020a) fue una campaña que inicio la colectividad paraguaya a fin de poder dar visibilidad y obtener de alguna manera respuestas.

Los registros de movilidad desde países Latinoamericanos, evidencian que llegaron en buses de larga distancia principalmente desde Argentina y Uruguay (ABC, 202ob).

En este mes según el MRE había 3.500 solicitudes de autorización para el retorno al país (IP, 202of).

También el aumento de establecimientos de cuarentena obligatoria en el Alto Paraná, registra un promedio de 1.965 platos de alimentos y agua mineral provistos por Itaipu Binacional para connacionales y 120 personas del equipo de apoyo logístico, además de proveer a los albergues de productos de limpieza, higiene y protección biológica, el mantenimiento de sanitarios portátiles, colchones, ropa de cama, alcohol en gel, detergentes, guantes y tapabocas, con una inversión aproximada de unos Gs. 1.070 millones ejecutada a través de la Oficina de las Naciones Unidas de Servicios para Proyectos (IP, 2020g).

Ainicios del mes de junio, informaban que más 5.300 personas ingresaron al país, por vías terrestre y área, además de que se mantenía al promedio de 3.500 personas para el retorno pero que el Estado considera que es un número cambiante, pero afirma "que la gran cantidad de interesados en volver, refleja que se están haciendo bien las tareas en cuanto al manejo del virus" (IP, 2020) y que $\mathbf{2 . 4 0 0}$ personas se encontraban en los albergues y hoteles salud.

El MRE informaba el 22 de junio que habían 7.400 connacionales retornados desde el mes de marzo (IP, 202oh) y que se mantiene un deseo de adquirir recursos básicos como insumos y alimentos para a sustentar a los albergues, sin embargo casi al finalizar el mismo mes el Centro de Coordinación Interinstitucional (CCI) informaba que se cumplían 100 días de habilitación del primer albergue en apoyo al Ministerio de Salud, con un total de 8.334 personas retornadas y que cumplieron o se encontraban cumpliendo con la cuarentena en algunos de los 70 sitios habilitados por el Estado, o en los 40 hoteles del sector privado, también informa que se habían organizado 12 vuelos humanitarios y 15 buses (IP, 2020i).

El predio de las FF.AA en el 
Cristando, P., Ruffinelli, R., García, B., \& Lo Bianco, A. Que la pandemia no nos robe la humanidad.

Paraguayos y paraguayas residentes en el extranjero y su derecho a regresar a su país.

departamento central fue reacondicionado por la SEN con la instalación de paneles tipo boxes particulares con instalaciones eléctricas, para albergara los connacionales, se solicitó la réplica del modelo innovador por parte de la Codena debido a la practicidad, privacidad y comodidad para los albergados en la experiencia del Operativo invierno (IP, 2020j).

En cuanto a los Hoteles Salud en este momento se señalaban 25 con 1.944 habitaciones, de las cuales 788 estaban ocupadas, y 1.156 libres, ubicados en Ciudad del Este, Hernandarias, Encarnación, Concepción, Salto del Guairá, Asunción y Central.

La iniciativa fue gestionada por los ministros de Turismo y Salud, el acceso estaba otorgado exclusivamente por los consulados paraguayos en el país desde donde se desea emigrar, los datos debían ser solicitados en las oficinas diplomáticas, donde se gestionan las reservas que deben ser costeadas por el connacional y para esto se establecieron tarifas sociales, acordes con el costo incluían desayuno, almuerzo, merienda y cena. El establecimiento de los Hoteles Salud en alguna medida se consideró como una reactivación del sector hotelero (IP, 2020e).

Para el mes de Julio se habían registrado un total de 10.000 a 11.500 connacionales ingresantes en los albergues desde el 23 de marzo ya que el 24 del mismo mes se dio el cierre de fronteras (La Nación, 2020c) y que se registraron unos 9.025 connacionales repatriados y que habían perspectivas del retorno de 1.300 connacionales con vuelos humanitarios y que en su gran mayoría serian provenientes de la Argentina (MDI, 2020).

En Alto Paraná se habilitaron 10 albergues para 512 personas, que estaban ocupados ya no solo por los connacionales, sino que también los casos positivos por circulación comunitaria u contacto, en este sentido se registraron a funcionarios penitenciarios y militares (La Nación, 2020d).

Las fuentes oficiales del Estado a través de las redes sociales informaban a la ciudadanía sobre los datos en referencia a la pandemia, así también se dio en el caso de la Secretaría Nacional de Inteligencia (SNI) desde el Twitter reportaba cantidades de connacionales como también desde que países retornaban, complementando los datos provistos por el ministro de Asuntos Internacionales, Federico González, de que en más de 4 meses habían retornado 11.500 y que en la República Argentina se habían inscripto 4.400 personas, y que se estaban realizando esfuerzos para el retorno (La Nación, 2020c).

Además de los 60 adultos mayores de 65 años, quienes guardaron cuarentena en el Centro Residencial Especializado de Atención y Apoyo para el Adulto Mayor del IPS, en San Bernardino, siendo el duodécimo grupo de repatriados desde Argentina (MRE, 2020a).

Otras de las respuestas de atención, constan a través del Ministerio de Relaciones Exteriores con sus consulados que se realizaron acciones solidarias con la entrega de cestas/canastas/kits de alimentos en Barcelona, España y São Paulo, Brasil (IP, 202ok) como en Argentina a grupos de Paraguayos residentes en 4 municipios en la provincia de Misiones que se entregaron elementos de prevención (MRE, 2020b).

La cancillería informó que a través de la gestión con la cooperación internacional y local se dotó al sistema de salud insumos y equipos médicos, con un valor 20 millones de dólares aproximadamente.

También la creación de una plataforma integrada por numerosos actores desde la Comisión ODS Paraguay, donde se obtuvieron donaciones por un aproximado de 2.300 millones de guaraníes, que fueron recibidas y administradas por el Programa de las Naciones Unidas para el Desarrollo (PNUD) y la Fundación CIRD. Estos recursos fueron destinados para compra de insumos y equipos médicos y alimentos para el área metropolitana y el interior del país (MRE, 2020a). 


\section{Conclusiones}

El pánico generado con la pandemia, tuvo un fuerte impacto en la población en general, así como en los paraguayos residentes en el exterior. La primera respuesta del estado a estos compatriotas fue el silencio, por lo que muchos de ellos buscaron la forma de volver al país por sus medios, en algunos casos para estar cerca de sus familiares en momentos difíciles. En otros porque la crisis económica afecto también los países donde residían, por ende, deseaban volver y buscar oportunidades en Paraguay.

Con el transcurso del tiempo, y en la medida en que la presión desde el exterior fue dándose por medio de las redes sociales, se fueron organizando los viajes humanitarios y los alojamientos en albergues y hoteles. Estos últimos con un fuerte componente de clase, los albergues para los pobres y los hoteles para los adinerados.

Las condiciones en los albergues no siempre fueron las mejores, ni siquiera por la calidad edilicia de los mismos y las comodidades. La vulneración de derechos en los mismos, está relacionada al poco respeto a la privacidad, la no diferenciación correcta de los espacios, el custodio amenazante de los militares en muchos casos, la poca socialización de información por parte del Ministerio de Salud, entre otras cosas.

No fue fácil la travesía por la que pasaron los connacionales, ni al momento de irse y mucho menos al momento en que desearon regresar. Los connacionales en el exterior son prácticamente abandonados por el estado paraguayo. Su derecho al voto es limitado, no son beneficiarios de ningún programa social y en muchos casos, siquiera son atendidos dignamente por las embajadas o consulados.

La mayoría de las actividades que observamos de los paraguayos residentes en el exterior, son auto gestionadas, en casos aislados acompañadas por la representación del estado en sus países. Tampoco se han observado vuelos humanitarios ni políticas públicas de regreso a la patria como si lo han hecho otros países en América del Sur

Por todo esto, es importante resaltar que la violencia estructural del estado, hacia los paraguayos residentes en el extranjero, tiene como componentes el abandono, la desidia, la falta de políticas públicas y en esta última etapa, la vulneración de sus derechos humanos, consagrados en tratados internacionales y en nuestra carta magna, principalmente el derecho a la vida.

La falta de respuesta efectivas por parte del Estado Paraguayo para con los connacionales se ha cobrado la vida de más de un centenar de personas, que fallecieron en tierras extranjeras, lejos de sus familias, lejos de sus afectos, lejos de sus raíces, muchos de ellos en espera de una respuesta por parte del Estado Paraguayo.

Cabe preguntarnos si esta situación servirá para que el estado paraguayo defina políticas públicas, hacia los paraguayos residentes en el extranjero, dándoles la importancia y relevancia que se merecen.

Hoy por hoy, la vulneración de sus derechos, es una forma de violencia estructural y sistémica, poniendo en serio riesgo su salud y sus vidas ante el avance de la pandemia a nivel mundial.

\section{Referencias}

Abc Color. (25 de Abril de 2020c). Más de 1670 Paraguayos están varados en el exterior. https://www.abc.com.py/ edicion-impresa/politica/2020/04/25/ mas-de-1670-paraguayos-estanvarados-en-el-exterior/

ABC, Color. (o3 de o7 de 2020). Esperan regreso de 1300 paraguayos desde el exterior. https://www.abc.com.py/ nacionales/2020/07/03/esperanregreso-de-130o-paraguayos-desde-elexterior/

ABC, Color. (12 de mayo de 2020b). Unos 3500 paraguayos quieren retornar al Paraguay. https://www.abc.com.py/ nacionales/2020/05/12/unos-3500paraguayos-quieren-volver/

ABC, Color. (24 de Mayo de 2020a). Migrar es un derecho, regresar también. 
Cristando, P., Ruffinelli, R., García, B., \& Lo Bianco, A. Que la pandemia no nos robe la humanidad.

Paraguayos y paraguayas residentes en el extranjero y su derecho a regresar a su país.

https://www.abc.com.py/edicionimpresa/sociales/2020/o5/24/migrares-un-derecho-regresar-tambien/

Attanasio, A. (19 de junio de 2020). Coronavirus en Paraguay: 3 claves para entender cómo el país logró contener el contagio pese a estar en la región "epicentro mundial" de la pandemia. BBC News Mundo. https://www. bbc.com/mundo/noticias-americalatina-53085660

Ayala, E. (2006). Migraciones. El Lector.

Benítez Cabral, J. (19 de o1 de 2020). El número de migrantes paraguayos en España creció 35 veces en dos décadas. $A B C$ COLOR. https://www.abc.com. py/edicion-impresa/suplementos/ economico/2020/o1/19/el-numerode-migrantes-paraguayos-en-espanacrecio-35-veces-en-dos-decadas/

Bourdieu, P. (2017). El Desarraigo, la violencia del capitalismo en una sociedad rural. Siglo XXI.

Comisión Interamericano de Derechos Humanos, CIDH. (2020). Pandemia y Derechos Humanos en las Américas. https://www.oas.org/es / cidh / decisiones/pdf/Resolucion-1-20-es.pdf

Dirección General de Migraciones del Ministerio del Interior, DGM. (marzo de 2020). Comunicado: Gobierno Nacional establece el cierre total de fronteras hasta el sábado 28 de marzo de 2020. http://www.migraciones.gov. py/index.php/noticias/comunicadogobierno-nacional-establece-el-cierretotal-de-fronteras-hasta-el-sabado-28de-marzo-de-2020

EFE. (23 de Abril de 2020). Paraguay a fronta la repatriación de ciudadanos con pocas plazas por la cuarenteno. https:// www.efe.com/efe/america/sociedad/ paraguay-afronta-la-repatriacion-deciudadanos-con-pocas-plazas-porcuarentena/20000013-4229412

eldiario. (25 de marzo de 2020). Paraguay repatriará a sus ciudadanos "vulnerables" varados en el exterior. https://www.eldiario.es/sociedad/ paraguay-repatriara-ciudadanosvulnerables-exterior_1_1000305.html

Giardini, M. (2019). La revolución en bicicleta. Servilibro.

HOY. (19 de Mayo de 2020). Albergues: 62 paraguayos vuelven a casa tras dar negativo al COVID-19. https://www. hoy.com.py/nacionales/albergues-62paraguayos-vuelven-a-casa-tras-darnegativo-al-covid-19

HOY. (o6 de Mayo de 2020b). Más de 6oo paraguayos en Argentina gestionan la repatriación y ya no hay fondos para ayuda. https://www.hoy. com.py/nacionales/mas-de-6ooparaguayos-en-argentina-gestionanla-repatriacion-y-ya-no-hay-fondospara-ayuda

IP. (o2 de Abril de 202ok). Consulados paraguayos entregan víveres a connacionales en situación de vulnerabilidad en el exterior. https:// www.ip.gov.py/ip/consuladosparaguayos-entregan-viveres-aconnacionales-en-situacion-devulnerabilidad-en-el-exterior/

IP. (05 de Mayo de 2020b). Más de 1.900 personas se encuentran cumpliendo cuarentena en albergues del Gobierno. https://www.ip.gov.py/ip/mas-de1-90o-personas-se-encuentrancumpliendo-cuarentena-enalbergues-del-gobierno/

IP. (o6 de Mayo de 2020g). Itaipu entregó más de 53.000 platos de alimentos a compatriotas que cumplen cuarentena en Alto Paraná. https://www.ip.gov.py/ip/ itaipu-entrego-mas-de-53-ooo-platosde-alimentos-a-compatriotas-quecumplen-cuarentena-en-alto-parana/

IP. (14 de Mayo de 2020f). Unos 3.50o paraguayos pidieron autorización para regresar a su país. https://www. telam.com.ar/notas/202005/463887paraguay-autorizacion--retorno.html

IP. (17 de Abril de 2020c). Disponen cierre de albergue transitorio en zona primaria del Puente de la Amistad. https:// www.ip.gov.py/ip/disponen-cierre- 
de-albergue-transitorio-en-zonaprimaria-del-puente-de-la-amistad/

IP. (21 de Mayo de 2020a). Habrá dos vuelos especiales para traer a paraguayos desde el exterior. https://www.ip.gov.py/ ip/habra-dos-vuelos-especiales-paratraer-a-paraguayos-desde-el-exterior/

IP. (22 de Junio de 2020h). Con unos 700 retornos previstos esta semana, Paraguay superará más de 8.000 repatriados durante pandemia. https:// www.ip.gov.py/ip/paraguay-concretaesta-semana-la-llegada-de-7oopersonas-y-con-ello-superaria-los80oo-retornos/

IP. (25 de Marzo de 2020l). Gobierno cuenta con 1.600 sitios para cuarentena de paraguayos que vengan del exterior. https://www.ip.gov.py/ip/gobiernocuenta-con-1-6oo-sitios-paracuarentena-de-paraguayos-quevengan-del-exterior/

IP. (26 de Junio de 2020i). Medida de albergues para cuarentena cumple 100 días con 8.334 repatriados: https://www.ip.gov.py/ip/medida-dealbergues-para-cuarentena-cumple100-dias-con-8-334-repatriados/

IP. (28 de Abril de 2020d). El 85\% de paraguayos que ingresaron durante la cuarentena lo hicieron desde el Puente de la Amistad. https://www.ip.gov.py/ip/ el-85-de-paraguayos-que-ingresarondurante-la-cuarentena-lo-hicierondesde-el-puente-de-la-amistad/

IP. (4 de Junio de 2020e). Hoteles Salud cuentan con disponibilidad para recibir a compatriotas en cuarentena. https://www.ip.gov.py/ip/hotelessalud-cuentan-con-disponibilidadpara-recibir-a-compatriotas-encuarentena/

IP. (4 de Junio de 2020j). Más de 5.300 connacionales ya ingresaron al país y para esta semana se coordinan más retornos. https://www.ip.gov.py/ip/ ya-ingresaron-al-pais-mas-de-5-300connacionales-y-para-esta-semanaaumentaria-el-numero/
IPA. (7 de Mayo de 2020). Cuarentena obligatoria es una estrategia fundamental para contener propagación, señalan autoridades de Salud. https://www.ip.gov.py/ip/ cuarentena-obligatoria-estrategiafundamental-contener-propagacion/

La Nación (21 de Julio de 2020c). En cuatro meses más de 11.500 compatriotas retornaron a Paraguay. https:// cdn-www.lanacionpy.arcpublishing. $\mathrm{com} / \mathrm{pais} / 2020 / 07 / 21 / \mathrm{en}$-cuatromeses-mas-de-1150o-compatriotasretornaron-a-paraguay/

La Nación. (23 de Mayo de 2020a). Hoy llegan más paraguayos del exterior: "Hay 86o habitaciones en 16 hoteles". https://www.lanacion.com.py/ pais/2020/o5/23/hoy-llegaran-masparaguayos-del-exterior-hay-86ohabitaciones-en-16-hoteles/

La Nación. (23 de Mayo de 2020d). Hasta ahora ingresaron al país más de 3.800 compatriotas. https://www.lanacion. com.py/pais/2020/05/23/hasta-ahoraingresaron-al-pais-mas-de-380ocompatriotas/

La Nación. (30 de marzo de 202ob). Un total de 324 paraguayos fueron repatriados este fin de semana. https://www. lanacion.com.py/pais/2020/03/30/ un-total-de-324-paraguayos-fueronrepatriados-este-fin-de-semana/

Méndez, I. (2008). Herederos de Stroessner. Asunción.

Ministerio de Relaciones Exteriores, MRE. (2020). Formulario de Asistencia. Paraguay.

Ministerio del Interior, MID. (o4 de Julio de 2020). Viceministro de Seguridad Interna participa de reunión evaluativae informativa del CODENA. http://www. mdi.gov.py/index.php/component/ $\mathrm{k} 2$ /item/12393-viceministro-deseguridad-interna-participa-dereuni $\% \mathrm{C}_{3} \% \mathrm{~B}_{3} \mathrm{n}-\mathrm{evaluat}$ iva-einformativa-del-codena

MRE. (o9 de Julio de 2020a). Adultos mayores de 65 años son repatriados 
desde Buenos Aires. https://www. mre.gov.py/index.php/noticias-deembajadas-y-consulados/adultosmayores-de-65-anos-son-repatriadosdesde-buenos-aires

MRE. (17 de Julio de 2020b). Consulado de Puerto Iguazú distribuyó elementos de prevención del coronavirus en municipios de la provincia de Misiones. https://www.mre.gov.py/index.php/ noticias-de-embajadas-y-consulados/ consulado-de-puerto-iguazudistribuyo-elementos-de-prevenciondel-coronavirus-en-municipios-de-laprovincia-de-misiones
TRECE. (14 de marzo de 2020). Coronavirus: ¿Cómo viven los paraguayos en el mundo?

Última Hora. (12 de Mayo de 2020). Covid-19: Jugadores paraguayos en el extranjero podrán retornar al país. https://www. ultimahora.com/covid-19-jugadoresparaguayos-el-extranjero-podranretornar-al-pais-n2884933.html

\section{Sobre los Autores}

Patricia Cristaldo

Trabajadora Social, Especialista en Planificación Estratégica Institucional, parte de equipo técnico de la Dirección de Trabajo Social. FACSO-UNA. Especialista en formulación, gestión y evaluación de proyectos sociales.

\section{Rosa Ruffinelli}

Doctoranda en Educación, UNA, Master en Trabajo Social, Licenciada en Trabajo Social por la UNA, Especialista en Educación y Rehabilitación con Enfoque Biopsicosocial, Docente Investigador de la UNA/FACSO, docente de la UNA/FENOB. Miembro del GT CLASCO Estudios Críticos en Discapacidad.

\section{Belinda García}

Licenciada en Trabajo Social, investigadora en áreas temáticas de género en mundo del trabajo rural y urbano, desarrollo rural y políticas públicas, diplomada en Investigación, Transferencia y Desarrollo en la Universidad Pública, UNA/FACSO.

\section{Alvaro Lo Bianco}

Docente, Psicólogo, terapeuta infantil. Especialista en Políticas Públicas para la Infancia y Adolescencia. Coordinador en el Ministerio de la Niñez y la Adolescencia. 